\title{
Analysis of the Impact of Charging Infrastructure Network on Urban
}

\author{
Power Network \\ Ren $\mathrm{Qi}^{1}$ \\ (Chongqing City Management College, Chongqing, 401331)
}

Keyword: Charging infrastructure network; Urban power grid; electric vehicle

Abstract: The superposition of the time and space of the grid can not only lead to local overload with random disorder in the large-scale electric vehicle, which Influences the stability, reliability and economy of the urban power grid operation in various degree. This paper analyzes the opportunities and challenges of the impact of charging infrastructure network on urban power grid, and provides reference for the government and the national power grid planning.

\section{Introduction}

As well as the development of battery and charging technology, energy and environmental issues make the development of electric vehicles as the representative of the new generation of energy saving and environmental protection that has become an inevitable trend. In order to adapt and promote the development of electric vehicle industry, domestic and foreign actively have launched electric vehicle charging infrastructure construction and demonstration operation as well as the electric car business model. The national grid and the southern Power Grid Corp in its power grid development planning have made it clear which to vigorously carry out electric vehicle charging and discharging key technology research and the corresponding business model to explore. They study in different stages of development of electric vehicles using charge discharge mode and discharge service infrastructure layout principle, and comprehensive application.

With the rapid development of electric vehicles in the future, the huge charging infrastructure network and charging service market will gradually form. The existing management and operation mode of urban power grid will be faced with challenges and opportunities in adapting to the development of electric vehicles.

The large-scale electric vehicle charging mode and its infrastructure network structure may have an important influence on the stability, reliability and economy of urban power network operation. However, different power supply modes and energy storage devices of large-scale electric vehicles provide an opportunity for the control load dispatch of power grid. Through proper charging and discharging load control strategy can not only effectively limit the adverse effects of charging load on urban power grid operation. But also for the city power grid peak regulation, frequency modulation, and promote renewable energy absorbing auxiliary services, create additional value and economic benefits. In this paper, the discussion of the electric vehicle is widely used in the power system, the positive and negative effects of the two aspects, to provide reference for the urban power grid planning.

2.Development status of charging infrastructure network in China

National Science and Technology Department has made it clear that China will "pure electric drive" as a strategic goal of technological transformation, and clear requirements to strengthen the vehicle

\footnotetext{
${ }^{1}$ Corresponding Author.

Email Address: 22151929@qq.com
} 
rental, battery leasing and other new business model research and exploration. With the frequent outbreak of the fog and haze in China, premier Li Keqiang chaired a State Council executive meeting in July 12, 2013, asked the government official vehicles, buses to take the lead in promoting the use of new energy vehicles, to improve the supporting facilities. Considered the battery replacement mode is convenient and easy to manage the battery charge and discharge, the basic business operation mode of electric vehicle is put forward, which is based on the national power grid, which is the main electric vehicle, which is replaced by electricity, and is supplemented by electricity. Which determined the development model of intelligent charging and switching service network, that fully support the charging and switching technology to meet the needs of electric vehicle users. As of June 2013, the national Power Grid Corp operating in the region have been completed and put into operation 360 standard charging stations and 15333 AC charging piles. As in Xuejiadao of Qingdao built charging storage integrated station. In Zhejiang Province, the network operation of electric vehicle charging and electric equipment is realized. In addition to the power grid enterprises investment, CNOOC and China Putian also set up a joint venture company, specializes in electric vehicle energy supply network. They have built 74 charging stations, service scale reached 4000 electric vehicles. In order to promote and adapt to the electric vehicle scale, commercial development, focus on different types of electric vehicles and battery power supply mode, related party interest of all grid enterprises at home and abroad, petrochemical enterprises are in the research and development of electric vehicle in different business model.

Because the scale and commercialization of electric vehicles will provide a good opportunity for the development of the power industry and the power industry, The power grid enterprises have the right to speak in the electric vehicle charging and discharging infrastructure construction and layout etc.. Therefore, in order to promote and adapt to the large-scale development of electric vehicles, to solve the corresponding problems of urban power grid safety operation and management mode, it is necessary for different operating mode of commercial electric vehicles, electric vehicles at home and abroad for different discharge mode, charging infrastructure network construction and operation mode and city power grid operation and management mode of in-depth investigation.According to the time and space characteristics of electric vehicle maintenance and its charging load in China, the research on technology, economy and management is carried out.

\section{The positive and negative effects of the charging infrastructure network on Urban Power Grid}

1) The positive impact of charging infrastructure network on Urban Power Grid

After the extensive use of electric vehicles, the impact on the power system has both positive and negative effects. After widely used in electric vehicles, it will become a new type of power system, large capacity load. For the power supply company, the rapid development and wide application of electric vehicles means that the huge increase in sales of electricity, which can promote the development of the power industry. In order to control the charging behavior of electric vehicles and to communicate with the dispatching center, the electric vehicle can be used as the energy storage equipment to provide ancillary services, such as the control of voltage and frequency. A large amount of electric vehicle batteries can be used for the power supply of FM and rotating standby, improve the reliability of power supply. At present, some scholars have put forward and analyzed the use of electric vehicles as a storage device of various ideas, Such as the use of electric vehicles as the peak power, frequency and spinning reserve, can stabilize the function of intermittent renewable energy utilization of electric vehicle storage, using electric vehicles for voltage control, such as the use of electric vehicles as the peak power, frequency and spinning reserve, stabilizing the function of intermittent renewable energy utilization of electric vehicle 
storage, using electric vehicles for voltage control.

Charge and discharge management of electric vehicles is reasonable by up to fill the valley and peak effect, namely by flattening the load curve, can boot to save the cost of power generation and group delay in generating units bear the peak load of investment. A large number of electric vehicle charging and discharging management and reasonable intermittent power (wind and solar) coordination effect can enhance the ability of power system, receiving intermittent power and improve, economy of system operation. To reduce carbon dioxide emissions: the advantages required depending on the circumstances, if the electric car charging electricity from new energy, it helps to reduce carbon dioxide emissions, if it is from the traditional coal-fired power plant, then access the electric car after car, two reduced carbon emissions and power system of new generating capacity increase carbon dioxide emissions are basically the same.

2) The negative effects of charging infrastructure network on Urban Power Grid

Wide application of electric vehicles, it will also cause an unprecedented challenge to the power grid. Charging of electric vehicles can lead to local areas of the load tension; electric vehicle charging time of the superposition or the peak load period of charging behavior will increase the burden on the distribution network. There are two solutions to this problem: distributed coordination and centralized coordination. Distribution coordination means that when the total current demand of the whole charging station is within the specified range, the charging current of each electric vehicle is maximum, thereby reducing the charging time. Centralized coordination refers to the intelligent judgment of the computer to coordinate the timing of charging the battery, the current size and the length of charge time, so as to achieve the purpose of the total current demand is not overloaded.

The main effects of the access of electric vehicles on the power quality of distribution network include voltage drop, harmonic pollution and unbalanced three-phase. Electric vehicles in the late night charge, will become the main equipment caused by voltage distortion, the harmonics generated by the transformer may be the life of the cable, as well as the impact of relay protection device. Only in the case of a large number of electric vehicles will bring the problem of three-phase imbalance, electric vehicle charging load should be a reasonable distribution between the three phases. Aiming at the most serious harmonic pollution problem, the following schemes are mainly adopted: implementation of the national standards related to harmonic, from the overall control of the power system harmonic level; increasing the phase number of converter device, commutation device is one of the main harmonic source, when the pulse number increased from 6 to 12, which can greatly reduce the harmonic current effective value; adding reactive power compensation device to improve the ability of the system to withstand the harmonic; the installation of filtering device, the harmonic pollution can be used in situ treatment approach, the local charging station to complete the work of harmonic control.

Influence on economic operation of distribution network: in the aspect of distribution network economic operation, the influence of the power distribution network loss and the power distribution transformer life is studied. The access to the electric vehicle will detract from the life of the distribution transformer. In particular, the negative impact on the transformer will become even more prominent when the users of electric vehicles use $240 \mathrm{~V}$ to charge and do not exert any control measures.

The power system is more sensitive to the disturbance of the electric vehicle, and the stability of the system is reduced after the interference. By the Nyquist criterion, the stability of the system with no electric vehicle load is higher than that of the system, which can resist all kinds of physical disturbance. This is mainly due to the special load characteristics of the electric vehicle charger, that 
is, the current harmonic and need more reactive power support. With a large number of electric vehicle access, resulting in an increase in the use of electric load, and the time and space uncertainty of the charging load will mainly affect the safety, economic operation and transmission network planning.

\section{Summary}

The superposition of large-scale electric vehicles random access to the grid in time and space will not only cause local overload, causing varying degrees of impact on city power at all levels, but also to the distribution network in the city, the peak valley difference of power quality and the power losses caused can not be influenced, thereby affecting the stability and the reliability and economic operation of city power grid. With the large-scale development of electric vehicles, through the analysis of the status of the charging infrastructure development in our country, this paper from two aspects of positive and negative analysis of charging infrastructure network opportunities and challenges to the development of city power grid, provide a reference for the relevant government departments and the national power grid planning department.

\section{References}

[1] Luo Zhuowei, Hu Zechun, Song Yonghua etc.. Electric vehicle charging load calculation method[J]. Automation of Electric Power Systems, 2011,35(14):36-42.

[2] Liu Peng, etc. Electric vehicle charging load model based on diffusion theory[J]. Automation of Electric Power Systems, 2012,32(9):30-34.

[3] Tu Yiyun etc. Research on the influence of electric vehicle on Power Grid[J]. Guangdong Electric Power, 2012, 25(5).

[4] Yang Shaobing. Load modeling method for electric vehicle charging station[J].Power System Technology, 2013,37(5):1190-1195.

[5] Feng Junqi. Analysis on scheduling parameters of electric vehicle charging and discharging storage integrated power plant[J]. Power System Technology, 2013,37(12):3325-3330.

[6] Uschi Buchinger, Sven Lindmark, Olivier Braet. Business Model Scenarios for an Open Service Platform for Multi-Modal Electric Vehicle Sharing[]. SMART 2013 : The Second International Conference on Smart Systems, Devices and Technologies: 7-14. 